\title{
'I JUST SAW THIS ON FACEBOOK, I NEED IT NOW': EXPLORING SMALL BUSINESS USE OF FACEBOOK
}

\author{
Naomi Augar \\ College of Business \\ Victoria University \\ Melbourne, Australia \\ naomi.augar@vu.edu.au \\ John Zeleznikow \\ College of Business \\ Victoria University \\ Melbourne, Australia \\ john.zeleznikow@vu.edu.au
}

\begin{abstract}
This paper reports on a study exploring social media adoption and use by twelve small businesses. Results indicate that Facebook is the dominant platform used and it can provide small businesses with a virtually cost free and easy way to reach customers. Businesses reported immediate results from using Facebook; customers arrived in store after seeing Facebook posts. Participants felt there were minimal risks involved and none had experienced negative feedback or inappropriate posts. Most felt that using Facebook increased their competitive advantage due to their enhanced online profile. Despite some effort to engage customers, business to consumer transfer of information is the primary function of the Facebook pages studied. Page owners report limited training for and analysis of their Facebook activities. This indicates a need for further research in the small business context, focused on approaches to boosting customer interaction, to realize the full potential of Facebook engagement.
\end{abstract}

Keywords: Facebook, small business, adoption, use, benefits.

\section{INTRODUCTION}

Social media allows users to generate content (posts) and respond to the posts of other individuals and organizations (Kaplan \& Haenlein, 2010) in an informal, social online setting. In recent years, businesses have recognized the opportunity to join the conversation and have moved into the social media domain (Harris \& Rae, 2009; Hopkins, 2012; Peters \& Salazar, 2010; Seo \& Rietsema, 2010; Singh, Davison, \& Wickramasinghe, 2010). Many businesses now have social media pages and customers are able to gather information about and review products and services and engage with businesses online.

The use of social media is second only to email in terms of online communication trends in Australia (Neilsen, 2012). Facebook is the dominant social media site in Australia, boasting almost half the total population as members (Cowling, 2012). Recent Nielsen (2012) market research indicates that there is an upward trend in consumer engagement with business via social media platforms in Australia. In 2010, 46 per cent of users had 'liked' a brand online; in 2011 this figure rose to 57 per cent (Neilsen, 2012).

In Australia 96 per cent of businesses are categorized as small businesses (Australian Bureau of Statistics, 2012), having 20 or less employees (Australian Bureau of Statistics, 2011). This equates to just over 2 million small businesses (Australian Bureau of Statistics, 2012). Only 700,000 of these businesses employ staff (Australian Bureau of Statistics, 2012). In recent times, the Australian retail 
sector has experienced poor to negative growth (National Retail Association, 2012) (relative to historical performance), which has challenged all retailers, large and small, to try to enhance their competitive advantage. Some are turning to social media.

To date, the majority of social media research exploring business adoption and consumer engagement has focused on medium to large organisations, e.g. (Jarvenpaa \& Tuunainen, 2012; Saundage \& Lee, 2011; Senadheera, Warren, \& Leitch, 2011; Seo \& Rietsema, 2010; Singh, et al., 2010). There is some research, e.g. (Hopkins, 2012; Rupert Hills \& Cairncross, 2011), focusing on why and how small businesses are using social media at present, but there is little work exploring what small business perceive as success in terms of social media engagement. Some international work focuses on Return on Investment (ROI) e.g. (Hoffman \& Fodor, 2010; Kaske, Kugler, \& Smolnik, 2012; Powell, Groves, \& Dimos, 2011), business value e.g. (Derham, Cragg, \& Morrish, 2011; Hopkins, 2012) and 'how-to' guides exist for businesses wanting to create a Facebook presence e.g. (Holzner, 2009).

This research augments the existing literature and contrasts this work with results exploring the adoption and use of Facebook in the small business context. Whilst the scope of the research initially included all social media, in identifying cases, it was found that the majority of small businesses who were potential participants only used Facebook. Hence the focus was narrowed. The paper first presents the theory and literature that framed the research. The research methodology is explained and a description of the twelve qualitative cases explored is provided. The paper then presents the results and an analysis of research findings before concluding with implications and opportunities for future work.

\section{BACKGROUND}

\section{Business Adoption and Use of Social Media}

Gallaugher and Ransbotham (2010, pp.199-200) characterize business and consumer interaction through social media via their 3-M framework: Megaphone (business sharing of information), Magnet (consumer interactions with business) and Monitor (consumer based interactions). Sharing information (Megaphone) with customers raises awareness about products and services within a customer base. However, the power of social media lies in the networked nature of the tool and its ability to reach far beyond the initial contact group, potentially broadening market share (Magnet and Monitor). To harness this potential network, businesses need to promote active customer participation via social media. That is, active posting techniques and interactions with their online customer base to ensure that customers understand the brand, product or service, the values and behaviours of the company (Jarvenpaa \& Tuunainen, 2012).

Active customer engagement can be developed through techniques including personalized feedback, contests and visioning scenarios (Jarvenpaa \& Tuunainen, 2012). Kaplan and Haenlein (2010, pp.6667) provide five useful points on being social. They identify the need for businesses to be active, interesting, humble, unprofessional and importantly, honest. These points posit that businesses should not simply use social media to pass on information to customers. The social nature of the platform requires businesses to adjust their communication style accordingly - social media communications need to be accessible and less formal than traditional business communication so as to engage users. This takes resources, time and knowledge to implement. In addition, a key ingredient to active engagement is achieving critical mass. Having a large number of consumers engaging with the site can enhance the chances of active discussion and engagement (Senadheera, et al., 2011). Understanding how established businesses promote their social media presence can be instructive. While obvious engagement metrics including the number of followers are important, the promotion of social media by a business is critical. Key facets to consider include the visibility of links to social network pages and the use of social network features (sharing or liking content) on organizational web sites (Peters \& Salazar, 2010). 
An engaged customer group have the potential to become brand ambassadors for a business through the promotion of products and services based on their own experience. Word of Mouth (WOM) marketing, the recommendation or promotion of a product through interpersonal exchanges within a network of consumers (Brooks Jr, 1957; Cao, Knotts, Xu, \& Chau, 2009) characterizes this phenomenon. Electronic word of mouth (eWOM) marketing, describes the extension of WOM marketing from physical social networks to those facilitated online (Nakayama, Wan, \& Sutcliffe, 2010) by web 2.0 platforms, including social media. Word of Mouth recommendations play an important role in influencing consumer decision making (Brown \& Reingen, 1987; Kaske, et al., 2012).

It is clear that companies, large and small are adopting social media to enhance their marketing capability and reach their customers. Finnair have used social media to support the renewal of their brand (Jarvenpaa \& Tuunainen, 2012), small craftspeople are using it to raise their profile (Holmes, McLean, \& Green, 2012) and restaurants are using social media to support marketing and relationship management and to respond to negative reviews on other sites (Derham, et al., 2011). Medium to large Australian based organizations are using social media for marketing, advertising, raising brand awareness, customer engagement and reducing advertising costs (Singh, et al., 2010). These themes are echoed in studies from New Zealand and England where small retailers used social media for customer engagement citing market penetration, and the absence of upfront costs as major factors in adoption (Harris \& Rae, 2009; Hopkins, 2012). Some companies believe that social media engagement increases their competitive advantage (Singh, et al., 2010) and creates business value (Derham, et al., 2011; Hopkins, 2012). In a recent case, an online retailer quantified business value in terms of impact on sales, which increased dramatically as a result of engagement via Facebook (Hopkins, 2012).

However, large organizations do not always find that social media reduces marketing costs. In fact, a key challenge for large organizations is the financial cost of resourcing social media engagement (Fueller, Schroll, Dennhardt, \& Hutter, 2012; Kuikka \& Äkkinen, 2011). Additionally, while small craftspeople appreciate that social media has no financial cost, they feel it costs them valuable time that they would otherwise dedicate to production (Holmes, et al., 2012).

Recent media coverage, e.g. (Cook, 2012; Moses, 2011), has highlighted the potential for negative or inappropriate posts that can harm business reputations. This is echoed by Gallaugher and Ransbotham (2010) who offer recommendations on managing risks including dissent and negative feedback via social media.

\section{Models of Technology Adoption and Use}

Seminal work by Davis (1989, p.320) identified that there are two major influencing factors in terms of an organizations adoption of technology: perceived usefulness and perceived ease of use. The OECD (1999) noted the need for a model to move beyond technology adoption, to chart the technology lifecycle. Their model mapped ecommerce readiness (motivations for and barriers to adoption), intensity (documenting the technology in action through observation and metrics on technology usage) and impact (understanding the benefits that technology adoption brings to the organization and beyond) as three key areas that chart the adoption and usage life cycle (OECD, 1999).

Fuchs et al. (2010, p.168) adapted the original OECD (1999, pp.6-7) model and Zhu and Kraemer's (2005, p.66) model of eBusiness adoption to present a detailed framework mapping readiness, intensity and impact in the eBusiness context. Fuchs et al.'s (2010, p.168) framework identifies several facets that impact business readiness to adopt technology:

- Organizational Context - IT resources required to get started, potential costs and benefits

- Environmental Context - the pressure the business perceives from competitors and customers 
- $\quad$ Firm Related Context - the size and type of the business

- Decision Maker's Context - the demographic, background and risk propensity of the decision maker (Fuchs, et al., 2010, p.168)

The framework maps the use of IT from adoption through day to day business to intensity and aspects of IT value are explored through impact on sales, efficiency, business relationships and customer satisfaction which are mapped to impact (Fuchs, et al., 2010, p.168). These models and framework provide a useful lens for exploring business Facebook adoption and use.

This research adopted the OECD readiness, intensity and impact model (1999) and the Fuchs et al. (2010) framework to guide exploration of the following key research questions:

- $\quad$ Readiness - Why do small businesses adopt Facebook and how do they resource their Facebook presence? Do they encounter barriers and risks when adopting Facebook?

- Intensity - How are small businesses using Facebook and how are their customers responding to their Facebook presence?

- Impact - What do small businesses believe are the benefits of using Facebook? Do they believe it provides their business with a competitive advantage and a good return on investment?

\section{METHODOLOGY}

The research used an exploratory multiple-case study approach (Yin, 2009) collecting data through a series of semi-structured interviews. A case study approach is considered appropriate when exploring Information Systems (IS) (Benbasat, Goldstein, \& Mead, 1987) and their use within organisations. Thirty minute interviews were conducted with representatives of twelve small businesses with 20 or less employees (Australian Bureau of Statistics, 2011) drawn from the retail, health and beauty sectors in Melbourne, Australia. Cases were identified through a purposive sampling approach involving internet searches focusing on small businesses with Facebook pages where the businesses were physically located in the Inner East and West regions of Melbourne. The retail sector was selected as the primary group for study due to the recent growth challenges experienced by the sector in Australia (National Retail Association, 2012). Several cases from the health and beauty sectors were also selected. While location and business type was not believed to influence Facebook adoption, use or perceptions of impact, different areas and businesses were selected for contrast.

The sample was further restricted to cases where the Facebook page had been established for more than a year with either $200+$ or less than 80 likes. These limitations were designed to identify diverse and polar cases (Eisenhardt, 1989) that might extend understanding of what business representatives perceive as beneficial in terms of Facebook engagement for small business.

Businesses were contacted in person to discuss the project and their ability to participate. The size of the final sample was limited to between 10-15 businesses. This limit aimed to provide enough scope to identify emergent themes while still retaining a manageable number of cases (Miles \& Huberman, 1994). 
Interviews were conducted with the retail store owner/manager or manager ${ }^{6}$. Participants were selfnominated by the businesses that volunteered to join the study. Due to the limited number of staff and the need to protect brand and reputation in small businesses, cases de-identified to protect the privacy of participants. Additional data was collected through de-identified observation of participating small business web and social media presences ${ }^{7}$ (Peters \& Salazar, 2010; Senadheera, et al., 2011).

Interviews were recorded and transcribed via a third party service to facilitate text based cross-case analysis (Yin, 2009). Transcriptions were reviewed and classified using a coding in detail approach using NVIVO to cluster codes into tree nodes (Bazley, 2007, p.69) that allowed for identification of emerging themes relating to Facebook adoption, usage, risks and benefits, ROI and competitive advantage; a cross-case synthesis approach (Yin, 2009). The interview results were augmented with results of site observations, which were classified to identify and confirm usage trends.

This study focuses on a limited sample of small retail, health and beauty businesses and the results are presented to provide insights into the themes around adoption, use and the value of social media perceived by small businesses. However, due to the sample size and restrictions the results are not representative, nor generalizable.

\section{RESULTS}

The final sample comprised six cases drawn from the East (E) of Melbourne and six from the West (W) of Melbourne, as noted in Table 1. Three quarters of the businesses were retail (R) focused, with two hairdressers (Beauty-B) and one Osteopathy clinic (Health - H) rounding out the sample. Participants were asked to describe the demographic of their typical customer. All responded that the vast majority were female. Seven participants could identify a broad age range from 15-60 years of age, with the majority citing 30-55.

\section{Readiness}

Participants were invited to discuss their business, their background and motivation for adopting Facebook, and their experience of getting it established. Several common themes emerged across the cases.

The interview participants were either the owner or a staff member within the business who was responsible for the social media presence. The only commonality within the participant group in terms of education and experience was that they had no technology background or formal technology or marketing qualification; every story was unique. Prior to becoming small business owners or managers, participants held a variety of roles from Zoo Keeper, Publisher to Scientist.

All participants reported some sort of experiential learning when adopting social media for their business. All but one participant had used Facebook in their personal lives prior to adopting it for business. A few participants reported learning more about tools and techniques informally through staff members, family or friends. Only two participants had attended specialist Facebook training. One had attended two one hour sessions of training which was provided free of charge to members of the local Chamber of Commerce. They found the training beneficial and noted that it was non-technical and focused on increasing dialogue with customers via Facebook.

\footnotetext{
${ }^{6}$ Mid-2012

${ }^{7}$ From mid-2012 through mid-20
} 
Participants were asked if they had a documented business or marketing plan. This question aimed to understand the degree of planning behind the decision to adopt social media. Only two companies had a marketing plan and two others had a business plan but no marketing plan. Social media use did not feature in any of the plans. The vast majority of businesses operated without any documented plans. As one participant put it, "No we don't [have a business plan], it is all in our heads (Case 10)."

As noted in Table 1, a common feature of all participants was their use of a Facebook page to promote their business. All but one of the businesses had established their Facebook site over a year ago, with most establishing their site in 2011. Facebook is the dominant social media platform in Australia, and this guided some participants when selecting the best platform to focus their social media activities. "At that time... there was MySpace and Facebook I think, and Facebook was the one that was starting to take over. We have never had anything to do with MySpace, all of the talk was surrounding the Facebook phenomenon at that stage (Case 12)."

However, as is noted in Table 1, a variety of other social media tools were adopted by a minority of businesses, ranging from a couple using Instagram and Flickr for photo sharing and management to Twitter, which was used by three participants for sharing information, but not to the same degree as Facebook (in one case Twitter had been dormant for some time). Pinterest, a relatively new image based social media platform was being used experimentally by two businesses to share images of products. Finally, three participants had a blog that they used for extended articles, which were not suited to Facebook. The dominant platform for all businesses was Facebook, hence the focus of the feedback gathered in interviews is the business experience with that platform.

\begin{tabular}{lcccccccccccc}
\hline Case & 1 & 2 & 3 & 4 & 5 & 6 & 7 & 8 & 9 & 10 & 11 & 12 \\
\hline Business Type & B & R & R & B & R & H & R & R & R & R & R & R \\
\hline No. staff & 8 & 4 & 4 & 4 & 5 & 9 & 2 & 5 & 4 & 8 & 2 & 4 \\
\hline Location & W & E & E & W & W & W & E & E & W & E & W & E \\
\hline Facebook & Y & Y & Y & Y & Y & Y & Y & Y & Y & Y & Y & Y \\
\hline Web site & Y & Y & Y & & Y & Y & Y & Y & Y & Y & Y & Y \\
\hline Ecommerce & & & & & Y & & & & Y & & & Y \\
\hline Twitter & & & & & & Y & & Y & & Y & & \\
\hline Pinterest & & & & & Y & & & & & Y & & \\
\hline Instagram & & & & & Y & & & & & & & \\
\hline Flickr & & & & & Y & & & & & & & \\
\hline Blog & & & & & Y & & & & & Y & & \\
\hline
\end{tabular}

Table 1 Small business participant overview

All interview participants noted that setting up their business Facebook page was relatively quick and easy. One participant noted "The reason I chose Facebook was because I knew how to use it and it was free (Case 7)." Another echoed this sentiment, "Because it is free, it is a free marketing tool (Case 1)." The absence of entry costs and the relative ease of use of the tool were cited consistently as enabling their use of it for business purposes. A few noted that their knowledge of the tool based on their personal 
use helped with the adoption decision, "I had already used Facebook as a personal user and it was all fairly intuitive, click here to make a business account... (Case 7)."

Participants indicated that very few, if any resources were needed to start and maintain a social media presence. Most established a presence with no help in a matter of minutes. Many used their own mobile phone to take photos and a personal or work computer to setup and manage the page; no specialist equipment or other resources were required.

Seven participants did not identify any barriers to the adoption of social media. One participant noted that some customers appeared to be opposed to the increasing use of technology in the business, but that this had not stopped adoption of social media, "... we have been doing a service for 15 years that we think we have done pretty well and it is just a time, like everything, that we have to move on (Case 3)." Interestingly, the two businesses who had adopted the largest range of social media tools, noted that time was the only barrier to use. One said, “...I just don't have time that is my main issue with social media is the time it takes (Case 10)." Another owner initially needed to be convinced by a staff member proposing Facebook adoption that the time spent would bring benefits to the business.

In identifying the key motivations for engaging with Facebook the participants cited sharing information and raising awareness about their business and products; brand awareness. They also felt it was important to maintain the immediate connection with their customers and to be visible online. A few participants used the word community when describing their motivation for establishing a Facebook page. They tried to provide value beyond promoting products and services by linking to articles and events related to their business, which might be of interest to customers. One third of the participants identified a desire to expand their customer base as a motivator for adopting Facebook.

Almost half of the participants described what can be summarised as competitive pressure as a motivator for adopting Facebook. The perceived pressure comes from observing other businesses; as one participant put it "I had been reading a lot about how businesses were reaching out in social media and it seemed to me that it was really important to be on that early on and getting to those people as soon as possible. You can get left behind very quickly in social media I find, so we jumped on board really quickly (Case 10)." The pressure also came from a need to be where their clients were, "Well once I got on Facebook and realised the whole world was on Facebook and Facebook is people's life, I realised that I had to get [my business] on Facebook (Case 4)."

As part of the interview participants were invited to discuss their perception of risk with relation to their social media presence. All participants were aware of the potential damage that could be caused to business reputation through inappropriate posts and negative reviews. However, all participants noted that they had not had any negative or inappropriate posts via Facebook. One business mentioned recent media coverage (Cooper, 2012) to indicate awareness of the pitfalls. Another felt that if that were to happen in the future they would deal with it as they might an in store or email complaint - by focusing on their "the customer is always right attitude (Case 5)." This sentiment was echoed by most participants.

\section{Intensity}

Participants were invited to discuss how they used Facebook to support their business. They described their posting habits and the customer engagement they received on Facebook. Table 2 summarizes the types of posts that businesses are placing on their Facebook page. Observation indicated that the majority of business posts were informational in nature with businesses describing and displaying (through embedded photos) new products in stock or services on offer. One participant noted the value of pictures (featured in posts by all businesses) and videos, "You know videos and pictures speak a lot louder than just words, so... [we]... try and have a visual which grabs the eye and makes the person want to actually click on it (Case 8)." 


\begin{tabular}{|c|c|c|c|c|c|c|c|c|c|c|c|c|}
\hline Case & 1 & 2 & 3 & 4 & 5 & 6 & 7 & 8 & 9 & 10 & 11 & 12 \\
\hline Likes & 44 & 72 & 72 & 246 & 248 & 410 & 430 & 491 & 715 & 727 & 1433 & 6242 \\
\hline Manager $^{8}$ & $\mathrm{C}$ & $\mathrm{O}$ & $\mathrm{O}$ & $\mathrm{O}+$ & $\mathrm{O}$ & $\mathrm{O}$ & $\mathrm{O}$ & $\mathrm{C}+$ & $\mathrm{O}+$ & $\mathrm{O}$ & $\mathrm{O}$ & $\mathrm{O}$ \\
\hline $\begin{array}{l}\text { Bus } \quad \text { Post } \\
\text { Freq. }{ }^{9}\end{array}$ & $1 \mathrm{pw}$ & $1 \mathrm{pq}$ & $2 \mathrm{pm}$ & $1 \mathrm{pw}$ & $\begin{array}{l}2- \\
3 \mathrm{pw}\end{array}$ & $1 \mathrm{pw}$ & $2 \mathrm{pw}$ & $3 p w$ & $2 \mathrm{pw}$ & $2 \mathrm{pm}$ & $7 \mathrm{pw}$ & $3 p w$ \\
\hline Product Info. & $\mathrm{Y}$ & $\mathrm{Y}$ & Y & $\mathrm{Y}$ & $\mathrm{Y}$ & $\mathrm{Y}$ & $\mathrm{Y}$ & $\mathrm{Y}$ & $\mathrm{Y}$ & $\mathrm{Y}$ & Y & $\mathrm{Y}$ \\
\hline Research Info. & & & $\mathrm{Y}$ & & & $\mathrm{Y}$ & & & & $\mathrm{Y}$ & & $\mathrm{Y}$ \\
\hline Humorous & & & & $\mathrm{Y}$ & & $\mathrm{Y}$ & $\mathrm{Y}$ & & $\mathrm{Y}$ & & $\mathrm{Y}$ & $\mathrm{Y}$ \\
\hline Staff & & $\mathrm{Y}$ & & $\mathrm{Y}$ & $\mathrm{Y}$ & $\mathrm{Y}$ & & $\mathrm{Y}$ & & & & \\
\hline Seasonal & Y & & $\mathrm{Y}$ & & & $\mathrm{Y}$ & $\mathrm{Y}$ & & $\mathrm{Y}$ & Y & Y & $\mathrm{Y}$ \\
\hline Event & & & & & $\mathrm{Y}$ & & & $\mathrm{Y}$ & & $\mathrm{Y}$ & Y & \\
\hline Competitions & $\mathrm{Y}$ & & $\mathrm{Y}$ & $\mathrm{Y}$ & & $\mathrm{Y}$ & $\mathrm{Y}$ & $\mathrm{Y}$ & $\mathrm{Y}$ & $\mathrm{Y}$ & & $\mathrm{Y}$ \\
\hline Pictures & $\mathrm{Y}$ & $\mathrm{Y}$ & Y & $\mathrm{Y}$ & $\mathrm{Y}$ & Y & $\mathrm{Y}$ & $\mathrm{Y}$ & $\mathrm{Y}$ & $\mathrm{Y}$ & $\mathrm{Y}$ & $\mathrm{Y}$ \\
\hline Videos & & & & & & & & $\mathrm{Y}$ & & & & \\
\hline
\end{tabular}

Table 2 Small business Facebook page data

A few businesses asked occasional questions of their followers to try and stimulate interaction. However, the majority of posts were 'closed in nature' (statements not explicitly inviting a response). Two thirds of businesses used Facebook to let customers know about competitions, special offers or promotions. Over half the businesses regularly featured humorous or light hearted, off topic posts. One participant noted the value of an informal, humorous post, “... at Easter I just randomly put up an album that was nothing to do with the shop which was just forty pictures of bunnies sitting in tea cups and when you see my user stats... it was ten times my usual access that weekend... (Case 7)" This post also reflects the trend for seasonal posts relating to events like Mother's day, Christmas, national events or public holidays. Two thirds of businesses featured posts relating to such events.

Businesses estimate that a very small proportion (less than $10 \%$ of their customer base) had liked their Facebook page, and of those who had, very few responded to business posts with a like or a comment. "I would say probably $80 \%$ use Facebook and how many engage? 5\%, not even (Case 4)." When discussing customer interaction one participant noted, "They might leave a comment or they might 'like' a photo on Facebook but generally I do not get a lot of interaction. I look at other peoples' and think they have got 500 people like that site or post, why doesn't anyone like mine? (Case 5)" Another participant noted, "If you don't put the price up it's always 'How much?' That is just your standard [comment] (Case 12)." Others felt that customers only responded if there was a competition or prize on offer. Observation of the business Facebook pages indicated that very few customers shared business

\footnotetext{
${ }^{8}$ The person who manages the Facebook page was either the Owner $(\mathrm{O})$ or staff member, known as a Champion $(\mathrm{C})$. In cases where staff assisted the primary administrator a + appears.

${ }^{9}$ Per week (pw), per month (pm) and per quarter (pq) - every three months.
} 
posts and few commented in response to business posts. The majority of interactions were a modest number of likes (relative to the number of page likes) for individual business posts.

\section{Impact}

Participants were invited to reflect on the benefits that using Facebook brought to their business. They were also asked their thoughts about whether Facebook provided a competitive advantage, return on investment, led to an increase in sales and increased customer satisfaction. Many common themes emerged across cases.

When asked about the impact that Facebook had on sales, several participants noted the virtually instantaneous results they received from posting a new product via Facebook. One commented that “... sometimes people come in 10 minutes after I have posted, so it is really immediate (Case 7)," noting that customers have come into the store and said, "I just saw this on Facebook, I need it now (Case 7)." This is echoed by another who found that Facebook "... definitely generates traffic, physical traffic. People come into look at something they have seen on Facebook, and that is good, or they will ring and ask about it (Case 9)." This trend went beyond the retail sector, to health services "Sometimes we will get people who we haven't seen for a while and they say 'I saw it on Facebook, I really need to come in (Case 6).,"

All of the businesses used other mediums to promote their businesses, several had used flyers and placed or continue to place advertisements in local newspapers. Most cross promote Facebook in these advertisements. However, many participants noted that they didn't feel that they received value from paid advertisements when compared with the value they gained from their Facebook page postings which they didn't have to pay to use. In contrast, one business noted that due to their modest following on Facebook, they felt that they got more value from targeted text message marketing to VIP customers on a regular basis.

All of the businesses promoted their social media presence to some degree. All businesses with web sites featured social media logos on their site. The majority of businesses also promoted their social media presence in store through in store signs, while a minority also encouraged sales staff to promote it direct to customers making a purchase. One company put stickers advertising their social media presence on every purchase as it is wrapped at the point of sale. When they established their Facebook page, they also purchased targeted Facebook advertisements to help boost their following.

Eleven businesses perceived their use of Facebook as providing them with a competitive advantage. Specifically, they felt that they had an advantage over their competitors who were not on Facebook. When asked if they felt Facebook provided a competitive advantage, one responded "Yes, I think so, compared to another gift shop 500 meters down the road, if they are not using Facebook then I just have that benefit of, that my logo pops up on peoples screen a couple of times a week when hopefully it will enter their mind to go and have a look (Case 7)." The business who did not agree felt that Facebook engagement had the potential to enhance competitive advantage, but given their modest following on Facebook, they felt that potential was yet to be realized.

When queried about the benefits versus the risks, all believed that Facebook engagement was worthwhile. Although few reviewed site analytics to inform their posting and management approach, and none had formally analyzed return on investment. As one participant put it "I don't really. The only way I evaluate the value of it is when I look at what they send you which is an update on how many potential people you have reached and I think it's worth it just to know that you have reached that many people, that they have looked (Case 4)." Another noted, "The only investment is time... it is definitely a good return for the time you put into it (Case 6)."

A few of the participants felt that customer satisfaction was enhanced by their social media presence. Some were enthusiastic about an increase in customer satisfaction, "Yes I think so, because I feel like I 
have become friends with some of my customers, that we have a better rapport because they have commented on something and I will say, 'thanks for your feedback idea, nice to see you in store the other day, how is the new job going?' and we just have a continued conversation (Case 7)." Another was more measured, "To a small degree, yes; we still do not have enough of our customers on there to really measure that (Case 10)." While another did not agree, "Customer satisfaction?...no I wouldn't think so (Case 12)."

\section{DISCUSSION}

Fuchs et al.'s (2010), framework highlights the role that the Decision Maker's Context plays in technology adoption or readiness. The results of this research indicate that the business owner or manager, the Decision Maker, plays a key role in Facebook adoption or readiness. However, their demographic, education and risk propensity, key attributes of a Decision Maker in Fuchs et al.'s (2010) framework, do not appear to influence readiness. Indeed all participants viewed Facebook engagement as a low or no risk activity. Rather, their experience with Facebook, and its perceived ease of use and usefulness (Davis, 1989) appeared to have a greater influence on readiness, and the decision to adopt social media. Familiarity, ease of use and usefulness were cited as key motivators for adoption. However, the Environmental Context (Fuchs, et al., 2010) does appear to be significant, an area that does not appear to be emphasised in the current social media literature. Most participants cited competitive pressure from similar businesses or their customers as motivating social media adoption.

The Organizational Context appears to be very strongly related to the Decision Maker's Context in the small business setting. Participants found that limited IT resources and skill were required to establish and maintain their Facebook presence. Only two had engaged in training, and while their endeavours had a larger audience and more engagement than some, others with no training had a bigger following. However, the absence of cost was a major motivator for small business adoption of Facebook. The perception of reduction in marketing costs aligns with other small and medium business findings (Hopkins, 2012; Singh, et al., 2010) but contradicts findings from large business that indicate social media adoption and management can incur significant costs (Fueller, et al., 2012; Kuikka \& Äkkinen, 2011). However, in one case where a cost effective alternative method (text messaging) with a larger audience was available, the perception of the value and impact of Facebook engagement was dramatically reduced as was the intensity of engagement. By contrast two other stores with similar Facebook followings perceived their Facebook presence to be beneficial.

A focused approach to adopting Facebook, limiting the range of tools used, publicising them both in store and on the business web site and posting on social media regularly (several times a week) seemed to achieve a desirable and manageable intensity as perceived by the majority of participants. Businesses have moved beyond pure product information and imagery to personalise posts through humour, seasonal themes, events, staff and competitions showing that many businesses have adopted the varied and informal posting style espoused by Kaplan and Haenlein (2010). In doing so businesses achieved the Megaphone facet of Gallaugher and Ransbotham's (2010) 3-M framework. However, the limited customer engagement noted by participants indicates that further research into understanding how to support Magnet and Monitor interactions is required to realize the benefits of eWOM for small business.

While most participants felt that their current practice provided a competitive advantage and ROI, further gains (e.g. eWOM/brand ambassadors) may be achieved by implementing further engagement and socialization techniques to facilitate greater customer interaction. It appears that a critical mass of followers may not have been reached by participants, which may also impact their ability to move toward Magnet and Monitor (Gallaugher \& Ransbotham, 2010) Facebook engagement. Further, promotion of Facebook to customers to engage more of their customer base, and analysis of their efforts using Facebook and sales data may also assist with meeting this objective. 
However, the immediate nature of customer response to postings (e.g. arriving in store to purchase or ringing up after seeing a product on Facebook) was also identified as an additional benefit or positive outcome by several participants. They perceived this to be an indicator that Facebook engagement had a positive impact on sales, a driver of value in Fuchs et al.’s (2010) framework.

Finally, perhaps due to the nature of their Facebook use, businesses did not highlight Impact on Efficiency or Impact on Business Relationships (Fuchs, et al., 2010) as drivers of value. However, several participants did feel that their Facebook engagement did have a positive impact on customer satisfaction, although this perception was not universal.

\section{CONCLUSION AND FUTURE WORK}

Several themes that augment and extend the current literature have emerged from this study into small retail business use of Facebook. The ease of use and usability of tools like Facebook provide small businesses with a virtually cost free channel for advertising their business and connecting with existing and potential customers. While customer interaction via Facebook is lacking for many of the small businesses studied, several perceive their Facebook presence as having a positive impact on sales due to the immediate reaction they receive from postings through customers visiting their store and mentioning Facebook posts.

The modest customer interaction observed indicates that some small businesses may benefit from training, further advertising and analysis of Facebook and sales data. Such activity may enhance customer engagement through creating dialogue and building participation numbers (likes or followers) to expand the reach of their Facebook presence. However, the relatively small Facebook audience and control over the customer service experience that the small businesses studied have, appears to diminish the risks perceived by business in terms of their engagement with Facebook.

This study indicates that Facebook is perceived to have many benefits and limited risks for the small retail, health and beauty businesses featured in this sample, warranting further research. Future survey based research will contrast the small businesses perspectives on Facebook adoption presented here, with a broader sample drawn from small businesses across Australia. It is envisaged that the national survey will enhance generalizability, providing results which have relevance for small businesses across Australia and beyond.

\section{REFERENCES}

Australian Bureau of Statistics. (2011). 8155.0 - Australian Industry Retrieved 8 June, 2011, from http://www.abs.gov.au/Ausstats/abs@.nsf/Lookup/8155.0Glossary12009-10

Australian Bureau of Statistics. (2012). 8165.0 - Counts of Australian Businesses, including Entries and Exits, Jun 2007 to Jun 2011 Retrieved June 1, 2012, from http://www.abs.gov.au/ausstats/abs@.nsf/mediareleasesbytitle/950EC94DB899312ECA2573B 00017B8F4? OpenDocument

Bazley, P. (2007). Qualitative Data Analysis with NVIVO. California: Sage Publications Inc.

Benbasat, I., Goldstein, D. K., \& Mead, M. (1987). The Case Research Strategy in Studies of Information Systems. MIS Quarterly, 11(3), 369-386.

Brooks Jr, R. C. (1957). "Word-of-mouth" advertising in selling new products. Journal of Marketing, 22(2), 154-161.

Brown, J. J., \& Reingen, P. H. (1987). Social Ties and Word-of-Mouth Referral Behavior. Journal of Consumer Research, 14(3), 350-362. 
Cao, J., Knotts, T., Xu, J., \& Chau, M. (2009). Word of Mouth Marketing through Online Social Networks. Paper presented at the Americas Conference on Information Systems, AMCIS 2009 Proceedings, Lima, Peru.

Cook, H. (2012). Coles Twitter campaign goes down, down gurgler Retrieved March 7, 2012, from http://www.theage.com.au/business/coles-twitter-campaign-goes-down-down-gurgler20120307-1uj4c.html

Cooper, M. (2012). What a whopper: spat rages over halal burger claims Retrieved June 4, 2012, from http://www.theage.com.au/entertainment/restaurants-and-bars/what-a-whopper-spat-ragesover-halal-burger-claims-20120202-1qugs.html

Cowling, D. (2012). Social Media Statistics Australia - March 2012 Retrieved June 1, 2012, from http://www.socialmedianews.com.au/social-media-statistics-australia-march-2012/

Davis, F. D. (1989). Perceived Usefulness, Perceived Ease of Use, and User Acceptance of Information Technology. MIS Quarterly, 13(3), 319-340.

Derham, R., Cragg, P., \& Morrish, S. (2011). Creating value: An SME and Social Media. Paper presented at the Pacific Asia Conference on Information Systems, PACIS 2011 Proceedings, Brisbane.

Eisenhardt, K. M. (1989). Building Theories From Case Study Research. The Academy of Management Review, 14(4), 532-550.

Fuchs, M., Höpken, W., Föger, A., \& Kunz, M. (2010). E-Business Readiness, Intensity, and Impact: An Austrian Destination Management Organization Study. Journal of Travel Research, 49(2), 165-178. doi: 10.1177/0047287509336469

Fueller, J., Schroll, R., Dennhardt, S., \& Hutter, K. (2012). Social Brand Value and the Value Enhancing Role of Social Media Relationships for Brands. Paper presented at the 2012 45th Hawaii International Conference on System Science (HICSS).

Gallaugher, J., \& Ransbotham, S. (2010). Social Media and Customer Dialog Management at Starbucks. MIS Quarterly Executive, 9(4), 197-212.

Harris, L., \& Rae, A. (2009). Social networks: the future of marketing for small business. Journal of Business Strategy, 30(5), 24-31.

Hoffman, D. L., \& Fodor, M. (2010). Can You Measure the ROI of Your Social Media Marketing? MIT Sloan Management Review, 52(1), 41-49.

Holmes, K., McLean, R., \& Green, G. (2012). Crafting a future online: A study of how independent craftspeople adopt social media and web technologies. Journal of Systems and Information Technology, 14(2), 142-154.

Holzner, S. (2009). Facebook marketing: leverage social media to grow your business Indianapolis: Que.

Hopkins, J. (2012). Can Facebook be an effective mechanism for generating growth and vallue in small business? Journal of Systems and Information Technology, 14(2), 131-140.

Jarvenpaa, S. L., \& Tuunainen, V. K. (2012). Company Tactics for Customer Socialization with Social Media Technologies: Finnair's Rethink Quality and Quality Hunters Initiatives. Paper presented at the 2012 45th Hawaii International Conference on System Science (HICSS).

Kaplan, A. M., \& Haenlein, M. (2010). Users of the world, unite! The challenges and opportunities of Social Media. Business Horizons, 53(1), 59-68. doi: 10.1016/j.bushor.2009.09.003

Kaske, F., Kugler, M., \& Smolnik, S. (2012). Return on Investment in Social Media--Does the Hype Pay Off? Towards an Assessment of the Profitability of Social Media in Organizations. Paper presented at the 2012 45th Hawaii International Conference on System Science (HICSS). 
Kuikka, M., \& Äkkinen, M. (2011). Determining the challenges of organizational social media adoption and use. Paper presented at the European Conference on Information Systems, ECIS 2011 Proceedings, Helsinki.

Miles, M. B., \& Huberman, A. M. (1994). Qualitative Data Analysis: An expanded sourcebook (2nd ed.). Thousand Oaks: Sage Publications, Inc.

Moses, A. (2011). Reputation wrecking: social media alarm sounds Retrieved April 5, 2011, from http://www.theage.com.au/technology/biz-tech/reputation-wrecking-social-media-alarmsounds-20110405-1d17z.html

Nakayama, M., Wan, Y., \& Sutcliffe, N. (2010). WOM or eWOM or Something Else: How Does the Web Affect Our Dependence on Shopping Information Sources? Paper presented at the Americas Conference on Information Systems, AMCIS 2010 Proceedings, Lima, Peru.

National Retail Association. (2012). Retail sector struggles with recessionary conditions Retrieved 1 June, 2012, from http://www.nra.net.au/images/120229-NRAMediaReleaseJanuaryRetailTrade-APPROVED.pdf

Neilsen. (2012). Media Release - Nielsen Australian Online Report 2011-12 Retrieved June 6, 2012, from http://au.nielsen.com/site/documents/TheAustralianOnlineConsumerReport-2012Info.pdf

OECD. (1999). Defining and measuring E-Commerce: A status report (Working Party on Indicators for the Information Society, Trans.) (pp. 19). Paris: OECD.

Peters, A., \& Salazar, D. (2010). Globalization in Marketing: An Empirical Analysis of Business Adoption and Use of Social Network Sites. Paper presented at the Americas Conference on Information Systems, AMCIS 2010 Proceedings, Lima, Peru.

Powell, G., Groves, S., \& Dimos, J. (2011). ROI of \$ocial media : how to improve the return on your social marketing investment. Singapore: John Wiley \& Sons.

Rupert Hills, J., \& Cairncross, G. (2011). Small accommodation providers and UGC web sites: perceptions and practices. International Journal of Contemporary Hospitality Management, 23(1), 26-43.

Saundage, D., \& Lee, C. Y. (2011). Social Commerce Activities - a taxonomy. Paper presented at the ACIS 2011 Proceedings, Sydney, Australia.

Senadheera, V., Warren, M., \& Leitch, S. (2011). A study into how Australian banks use social media. Paper presented at the Pacific Asia Conference on Information Systems, PACIS 2011 Proceedings, Brisbane.

Seo, D., \& Rietsema, A. (2010). A way to become enterprise 2.0: Beyond web 2.0 tools. Paper presented at the International Conference on Information Systems, ICIS 2010 Proceedings, Saint Louis, MI.

Singh, M., Davison, C., \& Wickramasinghe, N. (2010). Organisational Use of Web 2.0 Technologies: An Australian Perspective. Paper presented at the Americas Conference on Information Systems, AMCIS 2010 Proceedings, Lima, Peru.

Yin, R. K. (2009). Case Study Research: Design and Methods (Vol. 5). Thousand Oaks: Sage.

Zhu, K., \& Kraemer, K. (2005). Post-Adoption Variations in Usage and Value of E-Business by Organizations: Cross-Country Evidence from the Retail Industry. Information Systems Research, 16(1), 61-84.

An earlier version of this paper was presented at the Australasian Conference on Information Systems (ACIS) 2013 in Melbourne, Australia. 